\title{
Acumulación por desposesión, el caso de la empresa Audi en San José Chiapa, México ${ }^{1}$
}

\author{
Accumulation from dispossession, the case of Audi assembly plant in San José Chiapa, México
}

Susana Medina Ciriaco* | María de Lourdes Flores Lucero* | Guadalupe María Milián Ávila*

Recibido: 31 de diciembre de 2016

Aceptado: 20 de junio de 2017

\section{Resumen}

El capital se traslada a lugares donde puede revalorizarse a través de eliminar la propiedad inspirada en el Estado keynesiano o populista, reapropiándosela (Harvey, 2005). A esta característica actual del capitalismo Harvey $(2005 ; 2007)$ la denomina acumulación por desposesión. La pregunta de investigación es ¿existe este proceso en la instalación de la automotriz Audi, en San José Chiapa, México? El objetivo de la investigación fue indagar si la instalación de Audi en el municipio referido se puede caracterizar como un proceso de acumulación mediante desposesión, con base en las cuatro características propuestas por Harvey (2007): privatización y mercantilización, financiarización, la gestión y manipulación de la crisis y las redistribuciones estatales. Se acudió a fuentes documentales y de campo: seguimiento periodístico (20122016 y 2017) y visitas a la región, a los archivos del Registro Agrario Nacional (RAN), Fideicomiso Banco Estatal de Tierra (FBET), Archivo General del Estado (AGE), Instituto Nacional de Estadística y Geografía (INEGI). Se entrevistó a campesinos, habitantes del lugar y actores claves. La principal conclusión es que Audi desposeyó a los campesinos de la tierra y los recursos naturales con el concurso del gobierno local, quien trasladó los costos a través de impuestos a la población del lugar.

Palabras clave: acumulación por desposesión, financiarización, gestión y manipulación de la crisis, privatización y mercantilización, redistribuciones estatales.

\begin{abstract}
Financial resource is placed where it can be revalued through the elimination of land ownership inspired by the Keynesian or populist state, and then by re-appropriating it (Harvey, 2005). This current characteristic of capitalism Harvey $(2005,2007)$ names it accumulation by dispossession. The aim of this research is to understand the existing process in the setting up of the automotive plant of Audi, in San José Chiapa, México, and analyze whether this setting-up of Audi in the referred municipality can be characterized as a process of accumulation through dispossession, based on the four characteristics proposed by Harvey (2007): privatization and merchandising, financing, management and manipulation of the crisis and state and redistributions. Documentary and field sources were used: journalistic follow-up (2012-2016 and 2017) and visits to the region, files of the National Agrarian Registry (RAN), State Land Bank Trust (FBET), State General Archive, National Institute of Statistics and Geography (INEGI). Peasants, local inhabitants and key actors were interviewed. The main conclusion is that Audi dispossessed the peasants' the land and natural resources with the help of the local government, who transferred the costs through taxes to the local population.
\end{abstract}

Keywords: accumulation by dispossession, financing, management and manipulation of the crisis, privatization and commodification, state redistributions.

* Facultad de Arquitectura (FA), Benemérita Universidad Autónoma de Puebla (BUAP), Puebla, México. Contacto: renacerdelascenizas0@gmail.com

*FA, BUAP. Contacto: maria.flores@correo.buap.mx

* FA, BUAP. Contacto: mmilian@hotmail.com

Cómo citar: Medina, S., Flores, M. L., y Millán, G. (2017). Acumulación por desposesión, el caso de la empresa Audi en San José Chiapa, México Revista de Urbanismo, 36, 44-62. http://dx.doi.org/10.5354/0717-5051.2017.44778

\footnotetext{
${ }^{1}$ Agradecimientos: Al Proyecto “Gestión participativa para el mejoramiento de los asentamientos urbanos" con clave FLLM-ING16-G de la Vicerrectoría de Investigación y Estudios de Posgrado (VIEP) de la Benemérita Universidad Autónoma de Puebla (BUAP) durante el año 2016, a cargo de la Dra. María de Lourdes Flores Lucero, por el apoyo académico y económico. Al Consejo Nacional de Ciencia y Tecnología (CONACYT) por la beca otorgada para la estancia posdoctoral de la Dra. Susana Medina Ciriaco
} 


\section{Introducción}

San José Chiapa es un municipio del Estado de Puebla, México, que se encuentra al noreste del Estado (Enciclopedia de los municipios y Delegaciones de México, s.f). Su superficie es de $177 \mathrm{~km}^{2}$, cuenta con 27 localidades. En la cabecera municipal viven 4,821 habitantes, a una altitud de 2,367 metros sobre el nivel del mar. Está clasificado como un municipio suburbano según el tamaño de sus localidades (Instituto Nacional para el Federalismo y el Desarrollo Municipal, INAFED, 2015). Tiene 8,087 habitantes al 2010 (INEGI, 2010a), con una densidad de 45.68 habitantes por $\mathrm{km}^{2}$ (INAFED, 2015). Lo atraviesa la carretera 129 Acajete-Teziutlán. Se puede conocer la cabecera municipal a pie (observación directa).

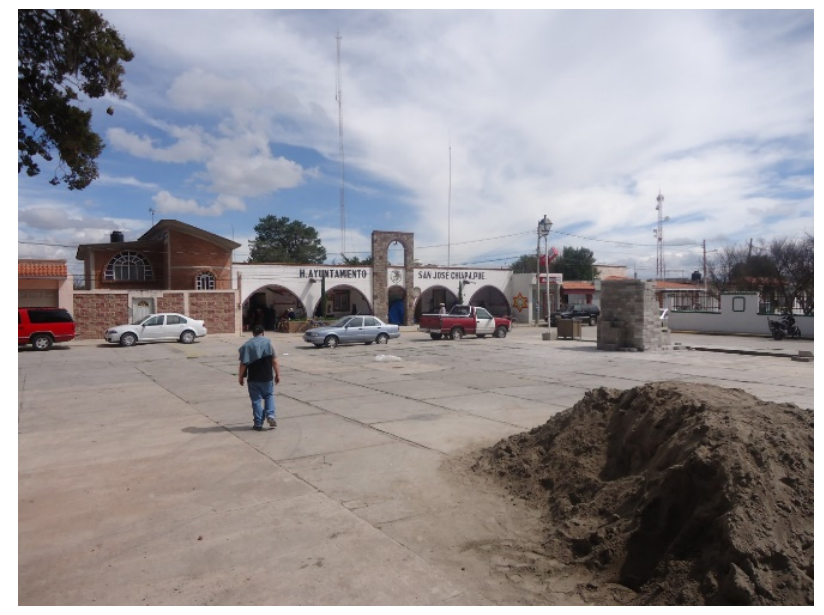

Imagen 1: La Cabecera Municipal de San José Chiapa, Puebla.

Fuente: Elaboración propia.

Es "un territorio con poblaciones marginadas con problemas de pobreza, insalubridad, abandono y segregación" (Sánchez y Hurtado, 2016, p. 11; Sánchez, Teutli, Hurtado, Saloma \& Mendoza, 2016, p. 642). San José Chiapa significa: “Chiapa, formado de chiahuitl, lodo senagoso, pantano, y $p a$, el; significa "en el pantano o en el cieno" (Secretaría de Gobernación, SEGOB, INAFED, Gobierno del Estado de Puebla, GEP, 2010). Los habitantes se dedican a la agricultura y la construcción. La primera ocupa una superficie de $111.39 \mathrm{~km}^{2}$. El área urbana ocupa una pequeña parte de la superficie territorial, al 2010, $2.63 \mathrm{~km}^{2}$ (INEGI, 2010a).
El 5 de septiembre de 2012, se anunció que la planta automotriz alemana Audi se construiría en el municipio de San José Chiapa (ver Mapa 1): "se debe a que Puebla cuenta con posibilidades de conexión logística, infraestructura adecuada, mano de obra calificada y calidad de vida" (González, 2012, s.p).

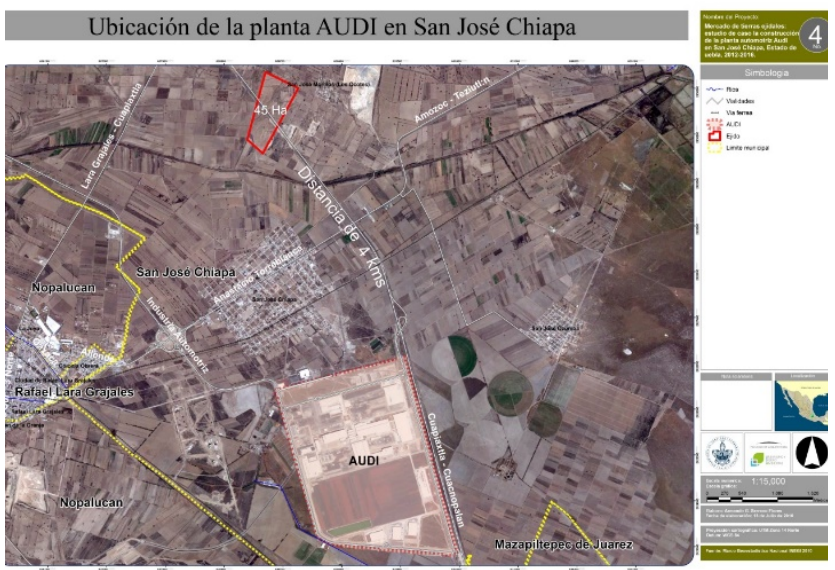

Mapa 1: Ubicación de la planta Audi en San José Chiapa.

Fuente: Serrano, A. (2016), con base en INEGI. (2010b). Marco Geoestadístico Nacional.

Se expide un convenio entre el gobierno estatal y municipal con Audi, para llevar a cabo su construcción. Ese acuerdo se mantiene en total confidencialidad e inaccesibilidad. En 2013, se coloca la primera piedra. En 2014, se inaugura el Centro de Capacitación. En 2015, dio inicio la producción preserie. En septiembre de 2016, se inauguró la planta y la producción de la camioneta tipo Premium Q5. El grupo invirtió US\$1.300.000.000, 3,800 empleados trabajan en su planta, y tendrá una capacidad a partir de 2017 de producir 150.000 unidades del Audi Q5. La superficie que ocupa son 460 hectáreas (has.). Tiene $1 \mathrm{~km}^{2}$ de área de contención, es decir, no se puede cambiar el uso del suelo establecido: agropecuario. Se generarán 20.000 puestos de trabajo indirectos y 1.000 nuevos puestos de trabajo justo al lado de la fábrica (Presidencia de la República, 2015; Audi México, 2014).

En los últimos 23 años ha habido cambios en los partidos que gobiernan al municipio. Actualmente es gobernado por el Partido del Trabajo (PT) (2014-2018), de izquierda. A nivel estatal gobierna el Partido Acción Nacional (PAN) (2011-2017), de corte derechista (INAFED, 2015). El gobierno estatal y la empresa han 
tratado con desdén al gobierno municipal, en entrevista con el Presidente Municipal de San José Chiapa, al mostrar una foto de la planta dijo: "aquí estaba yo, pero me quitaron" (J. Martínez, comunicación personal, 23 de abril de 2016, ver Imagen 2), de la imagen que originalmente eran cinco personas pero solamente aparecieron cuatro personas, entre ellas el gobernador y directivos de Audi y en la que se da a conocer la inauguración del Centro de Especialización (Audi México, 2014).

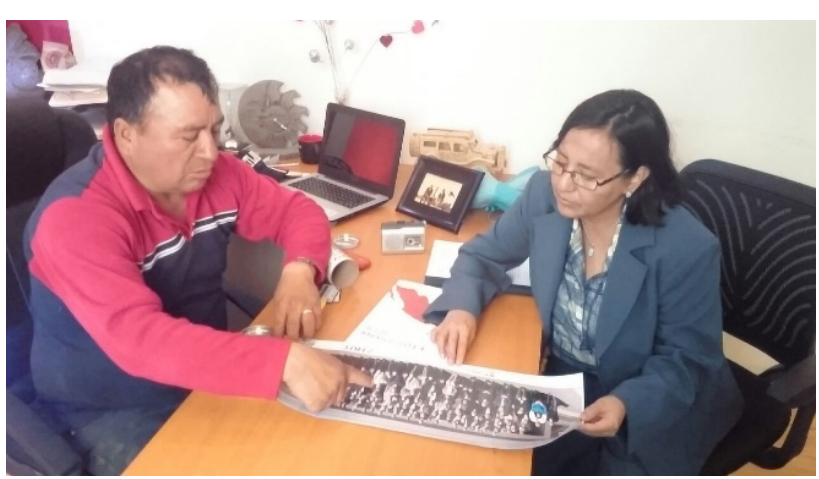

Imagen 2: Entrevista con el Presidente Municipal de San José Chiapa, Puebla. Fuente: elaboración propia.

\section{Planteamiento del problema}

En México, desde 1917 y hasta 1992, existió un régimen público para controlar el suelo, le llamaron ejidos $^{1}$, se hizo un reparto agrario y los beneficiados fueron los campesinos. El Estado mexicano, mediante el artículo 27 Constitucional, protegió la tierra considerada un bien público en usufructo de los ejidatarios. En 1992, el entonces presidente Carlos Salinas de Gortari cambió este artículo, transformando el ejido en propiedad privada y dio por concluido el reparto agrario (Bojórquez y Ángeles, 2014; Merchand, 2015). Las consecuencias, venta de tierra a precios desventajosos para los campesinos, afectando agua y aire, es decir, la mercantilización en masa de la naturaleza en todas sus formas (Harvey, 2005; 2007). "Todos estos procesos suponen una transferencia de activos de las esferas pública y popular a los dominios de lo privado y de los privilegios de clase" (Harvey, 2007, p. 167-168).

\footnotetext{
1 “Porción de tierra no cautiva y de uso público" (Harvey, 2007, p. 171). El territorio mexicano es de casi $2.000 .000 \mathrm{de} \mathrm{km}^{2}$, aproximadamente la mitad del territorio nacional son ejidos y un $75 \%$ de ellos están ubicados en la periferia de las ciudades (Bojórquez y Ángeles, 2014).
}

Uno de los rasgos característicos de la Acumulación por Desposesión (AD) es la privatización de todo (De Mattos, 2016), hasta los intocables como la tierra. El campesinado, ante la pérdida de su principal bien de subsistencia, se desplaza hacia las ciudades en busca de empleo (Costantino, 2016).

En este contexto, se expone lo siguiente: en San José Chiapa, el gobierno de la entidad hizo una inversión según algunos autores (García, E, 2016 a y b y Castillo, 2016) de $17.000 .000^{2} \mathrm{mmdp}^{3}$ para que Audi se asentara en el municipio. Con base en la revisión de diferentes fuentes periodísticas la inversión fue menor: \$14,977 mmdp ${ }^{4}$, es decir, 2 mdp menos que los que contabilizan algunos autores y se acerca el segundo monto con la cifra "que se calcula se destinaron del erario poblano directo a la empresa de al menos 10,000,000 mmdp de los cuales hoy se sabe que más de la mitad constituyen 'deuda oculta', es decir, por PPS" [Proyectos de Prestación de Servicios] (Hernández, 2017, p., 2). Camacho (2017) señala que esta última cifra "representa una sexta parte del presupuesto que maneja la entidad federativa en todo un año" (p. 1). El gobierno estatal compró tierra de uso común a los campesinos en MXN\$8.50/m ${ }^{2}{ }^{5}$, después el gobierno cedió la tierra de manera gratuita para que la empresa construyera su planta.

"Las comunidades pobres -en este caso San José Chiapa- ponen el territorio y los recursos naturales necesarios para la instalación de grandes empresas, pero los beneficios económicos no llegan a los pobladores originales de la región en donde se asientan las industrias, sino las ganancias se quedan en manos de transnacionales y empresas mexicanas vinculadas a funcionarios gubernamentales" (García, F., 2017, p. 2)

El objetivo de la investigación es indagar si la instalación de la Planta Audi en San José Chiapa se puede caracterizar como un proceso de $A D$, con base en los cuatro elementos propuestos por Harvey (2007): privatización y mercantilización, financiarización, la

\footnotetext{
2 Al tipo de cambio de 1 USD por 19.10 pesos mexicanos son $\$ 890,052,356$ USD.(20 de marzo de 2017).

${ }^{3} \mathrm{mmdp}=$ mil millones de pesos mexicanos.

${ }^{4} \$ 784,136,125$ USD.

${ }^{5} \$ 0.44$ USD.
} 
gestión y manipulación de la crisis y las redistribuciones estatales.

AD es una categoría analítica utilizada por David Harvey $(2005 ; 2007 ;$ 2010). Se refiere a la nueva etapa del imperialismo y sus manifestaciones en el territorio, como es el neoliberalismo y sus ajustes espaciotemporales.

Harvey (2005) plantea que Estados Unidos y Gran Bretaña, han sido incapaces de producir riqueza sin recurrir a la AD. Gómez (2015) dice que el neoliberalismo es un "orden global" (p. 121) y es ante todo una forma teórico-práctica de enaltecer las cualidades de los individuos por sobre las de la sociedad (Bojórquez y Ángeles, 2014). Theodore, Peck y Brenner (2009) destacan al neoliberalismo por su carácter político. El Estado ya no es un mediador como el keynesiano que promulgaba el papel central del gobierno para manejar el mercado y garantizar el pleno empleo (De Mattos, 2016).

De 1970 a 1990 surge el neoliberalismo (Harvey, 2007, 2010; Theodore et al., 2009). Su objetivo es la restauración del poder de clase (Harvey, 2007). Bush casi eliminó el impuesto aplicado a los ricos, denominado impuesto de sucesiones, mientras los impuestos a sueldos y salarios aumentaban (Harvey, 2007). El presidente de la Reserva Federal de Estados Unidos, "Paul Volcker, maquinó una transformación de la política monetaria estadounidense" (Harvey, 2007, p. 28-29) basada en el control de la inflación por sobre el pleno empleo que había reinado en el pasado.

Entre 1982 y 1984 México y otros países vieron en los préstamos de la Reserva Federal de EE.UU. y en el Fondo Monetario Internacional (FMI), una alternativa para salir de su precaria situación económica; la deuda se hizo impagable, para lo cual se utilizó el mecanismo de refinanciación, hecho que unió a la reserva federal de EE.UU. y al FMI.

Esta refinanciación significó la aplicación de medidas neoliberales en sus territorios, haciendo que los países se esforzaran cada vez más en aplicar medidas en contra de la población. A cambio de la reprogramación de la deuda, a los países endeudados se les exigía implementar reformas institucionales, como recortar el gasto social, crear legislaciones más flexibles del mercado de trabajo y optar por la privatización (Harvey, 2007; De Mattos, 2016; Vite, 2012).

\section{Antecedentes teóricos}

\section{Acumulación por Desposesión (AD)}

El término "Acumulación por Desposesión" ( $A D)$ tiene su origen teórico en El Capital de Marx, en las prácticas de acumulación primitiva (Harvey, 2005). Este autor observa que actualmente no se le puede llamar así, porque la sobreacumulación del capital se ha venido dando de manera persistente (Harvey, 2007).

Harvey (2005) expone que el capital ante un fenómeno de sobreacumulación se decide, con base en la presión de las clases ricas, a distribuir esta sobreacumulación a lo ancho y largo del planeta, sobre todo en los países marginados económicamente, de un lado sobreacumulación y, de otro, miseria. El capital crea

(...) un paisaje físico a su propia imagen y semejanza en un momento, para destruirlo luego. Esta es la historia de la destrucción creativa (con todas sus consecuencias sociales y ambientales negativas) inscripta en la evolución del paisaje físico y social del capitalismo (Harvey, 2005, p. 103).

Aparte de la "destrucción creativa" (Harvey, 2005, p. 103) también existe la "reciprocidad negativa" (Garibay y Balzaretti, 2009, p. 91), "el intento por obtener algo impunemente sin dar nada a cambio", como actúa la minera canadiense Goldcorp Inc., en Mezcala, Guerrero, México (Garibay y Balzaretti, 2009, p. 92).

Trabajos revisados utilizan el término acaparamiento global de tierras (Land-grab) ${ }^{6}$, como una manifestación de la AD (Hall, 2013); también para referirse a las adquisiciones de tierra dirigidas "a la producción y venta de alimentos y biocombustibles" (Santos, 2014, p. 334); al acaparamiento de tierra para extraer metales preciosos a través de cesiones (Barrera, 2013; Diego, 2014; Garibay, Boni, Panico y Urquijo, 2014); “La minería, el agua y la naturaleza del Altiplano boliviano" (Perreault, 2013, p. 1050); acumulación primitiva y mercantilización del agua (Roberts, 2008); "explotación de hidrocarburos; agricultura transgénica y la minería metalífera" (Gómez, 2015, p. 119); la AD y los conflictos socioambientales causados por la expansión de agronegocios en Argentina

\footnotetext{
${ }^{6}$ Land-grab sugiere la idea de arrebatar tierra antes de que alguien más lo haga (Composto y Rabasa, 2011).
} 
(Cáceres, 2015); la apropiación de tierra ejidal en una zona turística (Bojórquez y Ángeles, 2014); privatización de empresas públicas estatales; endeudamiento externo y la globalización bancaria (Vite, 2012).

Han surgido investigaciones que examinan la gentrificación y su vinculación con la $A D$, entendida la primera como "la creciente mercantilización de las ciudades y la perpetuación de las diferencias sociales a escala territorial" (Casgrain y Janoschka, 2013, p. 21), los estudios muestran la relación entre gentrificación, desplazamiento y hábitat (Janoschka, 2016), gentrificación en centros históricos (Inzulza-Contardo, 2016); se reflexiona si la gentrificación provoca desplazamientos (Davidson \& Lees, 2010); López-Morales (2013) expresa que "la gentrificación, más que simplemente 'reemplazo' de población, es una reestructuración urbana que genera desposesión de los valores de uso y cambio del suelo urbano, con un desplazamiento espacial o exclusión social en el acceso a la vivienda" (p. 38). La regulación social y la AD (Almeida Filho \& Paulani, 2011; Springer, 2013) va más allá, menciona que la AD provoca una homo sacer ${ }^{7}$ (p. 608).

La “Acumulación por Desposesión” (Harvey, 2007) tiene cuatro aspectos principales: privatización y mercantilización; financiarización; la gestión y la manipulación de la crisis, así como las redistribuciones estatales.

\section{Privatización y mercantilización}

Los EU, el FMI y el Banco Mundial (BM), han promovido en los países de América Latina, África y Asia la privatización, mercantilización y empresarialización, incluyendo los intocables que protegían a las clases más desfavorecidas (Costantino, 2016). En algunos casos bajo el pretexto de la seguridad alimentaria y en virtud de cierto déficit de tierra agrícola, los Estados árabes, Japón y China, después de la crisis alimentaria de 2007-2008, emprendieron acciones para proveerse de tierra agrícola (Borras Jr. y Franco, 2010).

\section{Financiarización}

\footnotetext{
7 “Vida que no cuenta para nada" (Springer, 2013, p. 608).
}

En 1980 se dio auge a la financiarización aprovechando la desregulación, permitiendo "al sistema financiero convertirse en uno de los principales centros de actividad redistributiva a través de la especulación, la depredación, el fraude y el robo" (Harvey, 2007, p. 168). Uno de los principales instrumentos es el endeudamiento por parte de las autoridades gubernamentales, que endeudan al gobierno y a la ciudadanía, lo que Harvey (2005) llama "servidumbre por deudas" (p. 113-114). "En el interior del sistema financiero existen innumerables formas de sisar ${ }^{8}$ valor" (Harvey, 2007, p. 168-169).

El sistema financiero, desde la década de los años sesenta y setenta del siglo pasado, se encuentra asociado a un tipo de competitividad en el que “... predomina la concurrencia oligopólica y la multinacionalización se impone en las estrategias empresariales" (De Mattos, 2016, p. 30).

\section{La gestión y la manipulación de la crisis}

Actualmente existe un aspecto relevante: "la difusión de "la trampa de la deuda» como principal instrumento de la acumulación por desposesión" (Harvey, 2007, p. 169 y 170). La forma es la transferencia de recursos económicos de los países pobres a los ricos. México ha vivido una crisis de endeudamiento desde 1980, "estas crisis de endeudamiento estuvieron orquestadas, gestionadas y controladas tanto para racionalizar el sistema como para efectuar una redistribución de activos" (Harvey, 2007, p. 169 y 170).

\section{Redistribuciones estatales}

En la $A D$ existe un mediador entre los gobiernos locales y las compañías transnacionales, el Estado. Para Merchand $(2013 ; 2015)$ la asociación del Estado con las empresas multinacionales es un "rasgo económicopolítico que definiría dicha acumulación por desposesión ya que la instrumentación para llevarse, necesita obligatoriamente que el Estado y los dueños del capital tengan el interés común 'contubernio'” (p. 107 y p. 78). Merchand (2012) menciona tres tipos de acumulación: ampliada, primitiva y "devaluación masiva de activos" ( $p$.

\footnotetext{
8 "Sisar: Parte que se defrauda o hurta. De sisa: (Del lat. scissa, cortada). F. Lo que se hurta en la compra diaria de comestibles y otras cosas menudas" (Harvey, 2007, p. 169).
} 
77). El Estado sienta todas las bases para que está desposesión ocurra, ya sea a través de la violencia o de la imposición de lo que consideran la legalidad (Costantino, 2016; Harvey, 2005). Dice Bauman (2002/2004):

(...) y su reciente adquirida capacidad de movilidad espacial alcanza, en la mayoría de los casos, para extorsionar a los agentes locales de la política y obligarlos a acceder a sus demandas. La amenaza (aún callada y meramente adivinada) de cortar con sus compromisos locales e irse a otra parte es algo que todo gobierno responsable, por su propio bien y el de sus electores, debe considerar con toda seriedad, intentando subordinar sus políticas al imperativo primordial de evitar el peligro de la fuga de capitales. En la práctica, esto significa bajos impuestos o nulas regulaciones, y por sobre todas las cosas 'flexibilidad laboral' (p. 159-160).

\section{La violencia y represión hacia los grupos marginados}

La oposición a la $A D$ es reprimida fuertemente por el Estado (Guerra y Skewes, 2010), “es decir, el uso de violencia como política de Estado para resolver los conflictos a favor de los más poderosos" (Costantino, 2016, p. 146). “El Estado neoliberal asume enseguida la función de la represión activa, hasta el punto de establecer un estado de guerra de baja intensidad contra los movimientos opositores" (Harvey, 2007, p. 171-172). Dice Bauman (2002/2004) que al final se tiene "una población dócil, indolente e incapaz de oponer resistencia organizada a las decisiones que el capital puede tomar" (p. 159-160).

\section{Enfoque, método, metodología e instrumentos}

Se analiza la instalación de la armadora Audi en San José Chiapa, desde el enfoque neomarxista. Se entiende por este último a corrientes de pensamiento que tienen su origen en el legado teórico de Karl Marx, pero que han adaptado sus ideas a las circunstancias actuales (Fair, 2010). Harvey deriva sus análisis de las lecturas económicas de Marx y las aplica al mundo actual (Torres, 2015), por lo que se trata de un autor neomarxista.

El método marxista es la dialéctica. Este último, es una forma particular de reconstruir y sistematizar, conceptual y empíricamente, los fenómenos de interés científico. En Marx y en sus discípulos la dialéctica se aplica al estudio a través de categorías analíticas (Nateras, 2005). En Harvey, asume su forma actual a través del concepto de Acumulación por Desposesión y las categorías que la componen y que ya se han señalado.

Desde el punto de vista metodológico, se diseñó una ruta que contempló hechos, actores e instituciones: la compra de la tierra por el gobierno, su cesión a la empresa, los eventos que mediaron la compra, venta y cesión de la tierra, los actores que participaron, así como las instituciones gubernamentales y sociales involucradas. Los instrumentos que se utilizaron fueron los recorridos de campo, entrevistas a los actores claves, así como la visita a los archivos municipales y estatales (Rojas, 2011).

\section{Descripción del caso de estudio}

En la reunión de la Comisión de Hacienda y Patrimonio Municipal (CHPM), del Congreso del Estado de Puebla, del 23 de julio de 2012, "en el punto cinco, se aprobó por unanimidad el proyecto de dictamen con minuta de Decreto por el cual se reformaron y adicionaron diversas disposiciones de la Ley General de Bienes del Estado" ( $\mathrm{H}$. Congreso del Estado de Puebla, HCEP, CHPM, 2012a, p. 1).

El 25 de julio de 2012, se realizó una segunda reunión de la Comisión con funcionarios de la Secretaría de Administración del Gobierno Estatal para tratar la Ley antes comentada, la cual estipula que:

El propósito general de la Reforma [es] la generación de un marco normativo para robustecer las relaciones que mantiene el gobierno del Estado con particulares interesados en invertir en infraestructura de la entidad, pudiéndose llevar a cabo concesiones de bienes de dominio público, aumentando las inversiones que se hagan en servicios y bienes sin destinar recursos presupuestales para su ejecución, que generará derrama económica y fuentes de empleo en la entidad. Por otro lado precisó que las concesiones permitirán que el gobierno estatal no recurra a la deuda pública para funcionar en esas actividades" (HCEP, CHPM, 2012b, p. 1).

La CHPM se reunió el viernes 14 de septiembre de 2012, para abordar tres puntos relacionados con Audi: 
En el punto dos se aprobó por unanimidad la iniciativa de decreto por el que se establecieron apoyos para el desarrollo, construcción, instalación y operación de empresas de manufactura y ensamblaje de automóviles. En el punto tres se aprobó por unanimidad la iniciativa de Decreto por el cual se autorizó la enajenación de un inmueble conformado de 460 hectáreas ubicadas en el municipio de San José Chiapa, Puebla, en términos del convenio de desarrollo celebrado entre el Estado de Puebla con Audi automotive, S.A. de C.V. y Volkswagen de México, S.A. de C.V. En el punto cuatro se aprobó ... la adhesión del Honorable Ayuntamiento del municipio de San José Chiapa, Puebla, al convenio de desarrollo celebrado entre el Estado de Puebla con Audi automotive, S.A. de C.V. y Volkswagen de México, S.A. de C.V." (HCEP, CHPM, 2012c: 1, el subrayado es de las autoras, ver Imagen 3).

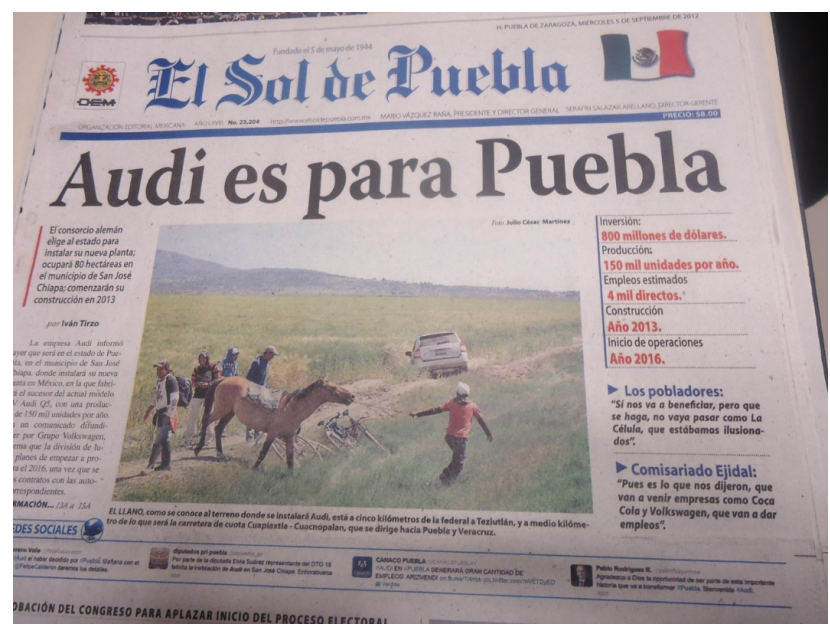

Imagen 3: Audi es para Puebla.

Fuente: Martínez, J. (2012). Audi es para Puebla. [Nota periodística]. Recuperada de El Sol de Puebla.

En este contexto, el 19 de septiembre de 2012 el Congreso del Estado de Puebla expidió un Decreto mediante el cual:

Se autoriza al titular del Poder Ejecutivo del Estado, a realizar los trámites necesarios para llevar a cabo la transmisión de la propiedad de los bienes inmuebles correspondientes al Sitio del Proyecto, en términos del contrato del desarrollo suscrito por el Gobierno del Estado de Puebla con AUDI automotive, S.A. de
C.V. y Volkswagen de México, S.A. de C.V.) (GEP 2015a, el subrayado es de las autoras).

En la misma fecha del Decreto anterior, "se autoriza la adhesión del Honorable Ayuntamiento del Municipio de San José Chiapa, Puebla al Convenio de Desarrollo celebrado entre el Estado de Puebla con AUDI automotive, S.A. de C.V. y Volkswagen de México, S.A. de C.V" (GEP, 2015b).

(...) la referida aprobación se dio por unidad de votos de todos los integrantes del Honorable Cabildo del municipio de San José Chiapa, y en cumplimiento por lo dispuesto por el artículo 57, fracción VII, corresponde al Congreso del Estado, aprobar los contratos que celebren los Ayuntamientos cuando tengan duración mayor del periodo para el cual fueron electos (GEP, 2015b). 


\section{Resultados}

Se presentan los resultados obtenidos en la investigación, tomando como punto de referencia el concepto teórico Acumulación por Desposesión (AD), con base en sus cuatro características principales: privatización y mercantilización, financiarización, la gestión y la manipulación de la crisis y redistribuciones estatales, se proporcionan ejemplos del caso de estudio.

\section{Privatización y mercantilización}

El Estado es sustituido como agente, su lugar es ocupado por el mercado y agentes privados.

Las tierras en San José Chiapa. El gobierno del Estado de Puebla cedió ${ }^{9}$, regaló la tierra a la empresa Audi (460 has.). Este no es un hecho aislado. En otras entidades como Guanajuato (Toyota) y Nuevo León (Kia Motors), los gobiernos locales se colocaron al servicio de los intereses de las empresas automotrices, incurriendo en actos de corrupción. El ex secretario de Desarrollo Económico "fue vinculado a proceso por presuntas anomalías derivadas de las facilidades otorgadas a la empresa Kia Motors para que se estableciera en la entidad, que representan un desvío de 3'683,504 mdp" (Alanís, 2016).

Sobre este tema, se le preguntó al alcalde ¿Cuál fue la actitud de los dueños de la tierra ante la expropiación?:

Expropiación no hubo, no expropiaron nada, se compraron los terrenos, digo a lo mejor los de uso común fueron a un precio muy bajo porque también igual se platicó con todo el pueblo, se les comentó a los jefes, se platicó con ellos y se llegó a un acuerdo por buscar un beneficio para la comunidad, la misma gente de aquí del municipio que estuvo en la reunión y con ellos se planteó la situación que se iba a establecer la empresa y pues también platicamos de los pros y de los contras y tuvimos que ver a los ejidatarios y convencerlos de que también se aceptara la negociación para la compra de los

\footnotetext{
${ }^{9}$ En los diferentes documentos emitidos por la Cámara de Diputados se dice que fue una concesión de bienes de dominio público, en otros, una transmisión de la propiedad de los bienes inmuebles y también se maneja como la enajenación de un inmueble (ver subrayados en el caso de estudio).
}

terrenos a muy bajo precio para beneficiar a la mayoría de la gente, porque la intención es que como gente de la región tengamos algún día el privilegio de estar en un trabajo estable, porque la verdad aquí en San José Chiapa la gente nos dedicamos a la agricultura y a la construcción, y tenemos que la agricultura aquí la gente se establece pero ya es un $30 \%$ de la gente y el otro $70 \%$ pues tenemos que salir a trabajar a Puebla, a México, pues a donde ocupen la gente de la construcción" (J. Martínez, comunicación personal, 23 de abril de 2016).

\section{El precio de la tierra y el despojo de las tierras de} uso común. En fechas cercanas al anunció de la instalación de Audi, llegaron funcionarios de Tenencia de la Tierra (TT), del gobierno estatal, con el fin de comprar terrenos al ejido de San José Chiapa. Un ejidatario dijo que "a ellos les decían que era para instalar unas naves industriales" (A. Hernández, comunicación personal, 30 de septiembre de 2016). Los empleados de TT fueron desplazados como negociadores por el Fideicomiso Banco Estatal de Tierras (FBET).

La secrecía logró evitar que el precio de la tierra se elevara, si los campesinos se enteraban que era para Audi. El precio pagado por el gobierno por las tierras de Audi fue de MXN\$8.50 $0^{10}$ el $\mathrm{m}^{2}$ (MXN\$85,000 ${ }^{11}$ por ha), mientras que las tierras que se vendieron para la Ciudad Modelo $^{12}$ tuvieron un costo de aproximadamente $\operatorname{MXN} \$ 17^{13} / \mathrm{m}^{2}$ (MXN\$170.000 $/ 4$ ha). La diferencia entre

\footnotetext{
${ }^{10} \$ 0.44$ USD.

${ }^{11} \$ 4.449,17$ USD

${ }^{12}$ Ciudad Modelo, también llamada 'Ciudad Audi' (Hernández, 2015, p. 2). Casi al mismo tiempo de decidir el emplazamiento de la empresa automotriz Audi (septiembre de 2012), El Gobierno Federal dio a conocer la creación en la localidad de San José Chiapa, Puebla de una ciudad ideal con todos los servicios, un nuevo centro urbano, una nueva urbe, que refleja la privatización del espacio urbano (Hogan, Bunnell, Pow, Permanasari \& Morshidi, 2012). Destinada "para los trabajadores de la zona industrial de San José Chiapa a fin de reducir el tiempo de traslado de los empleados y proveerlos de todos los servicios necesarios, incluso, de tiendas departamentales" (e-consulta, 2014). "Se trata de una ciudad modelo que tenga transporte con movilidad muy accesible, mucho lugar para esparcimiento $y$, por supuesto, que sea sustentable y económica" (Hernández M., 2015, p. 3). Contreras (2011) señala que es "un constructo social que expresa un modo de vida determinado 'el citadino'" (p. 90). En esta ciudad, como dice Hidalgo (2004), "se llevan a cabo proyectos inmobiliarios fuera de los límites de las ciudades, que ocupan suelo rústico en comunas ajenas a dicho perímetro" (párrafo 8 ).

${ }^{13} \$ 0,89$ USD.

${ }^{14} \$ 88.983,39$ USD.
} 
la venta de los terrenos para Audi y Ciudad Modelo se reflejó en los precios. Habrá que tomar en consideración que las tierras para la armadora eran tierras de uso común que, "eran tierras de las que no se beneficiaban mucho los del ejido, porque no eran ellos quienes llevaban a pastar sus animales" (M. Valencia, comunicación personal, 20 de octubre de 2016).

En entrevista, uno de los ejidatarios explicó:

A los ejidatarios y cuando se vendió pues si nos beneficiamos ... pero pues sí, de las ventas si hubo beneficio el precio casi vino del Banco Estatal de Tierra y Tenencia de la Tierra, vinieron y ellos fijaron el precio, porque nos dijeron venimos de parte del gobierno y el gobierno les va a pagar esta cantidad y si les conviene o ustedes dicen si les conviene sino pues esta empresa se va a ir a otro lado. Por eso precisamente fue una primera venta de 8.50 y luego ya de 17 por lo mismo de que ya nos enteramos de que era una empresa grande. Se nos dijo que algo bueno llegaría al municipio ${ }^{15}$ (J. Contreras, comunicación personal, 20 de octubre de 2016).

Mientras se enteraban vendieron tierras de uso común al gobierno que más tarde la cedió a Audi. El precio fue de MXN\$8.50/m². MXN\$1.50 más comparado con lo que les intentaron pagar a los ejidatarios de San Salvador Atenco, en $2001\left(\mathrm{MXN \$ 7^{16 }}\right.$ ), quienes rechazaron la ubicación de una terminal aérea en su territorio (Alfaro, Guízar y Vizcarra, 2011).

La transformación de San José Chiapa. En mayo de 2013 se colocó la primera piedra de la nueva planta, lo que empezó a modificar el orden social agropecuario del lugar, sostenido a partir de la producción de maíz, lechuga, zanahoria y un poco de ganado. De acuerdo con el alcalde de San José Chiapa:

De 2012 a la fecha más de 15 inversionistas, desarrolladores de vivienda, comerciantes, empresarios gasolineros, del ramo hotelero, bancario

\footnotetext{
${ }^{15}$ El gobierno estatal ideologizó la llegada de la armadora, creando la ilusión de un supuesto progreso. "El gobernador detalla lo que viene en los próximos años y lo que significa la inversión de Audi: un nuevo polo de desarrollo para la entidad que implique oportunidades de trabajo, que implique una derrama económica extraordinaria, esto sin duda nos va a hacer el clúster automotriz más importante del país" (Rueda, 2012, s.p.).

${ }^{16} \$ 0,36$ USD.
}

y restaurantero, visitaron la región en busca de establecer nuevos negocios; sin embargo, se les pide que aguarden a la publicación del Programa. Al municipio llegaron más de 4,000 hombres-camión que en más de 11 meses trasladaron material para la construcción de las plataformas de soporte de las primeras naves industriales de la nueva armadora de autos de lujo. La calma que por años reinó en el municipio de unos 9.000 habitantes, dedicados a la agricultura y la construcción, pronto se vio invadida por especuladores inmobiliarios. El $\mathrm{m}^{2}$ de terreno en ese municipio y poblaciones aledañas, se cotizaba entre US\$0.31 y US\$1.04, y tras la decisión de Audi de invertir US\$1.300.000.000 en su nueva fábrica, en la zona centro del Estado de Puebla, el precio por la misma extensión de territorio aumentó de US\$10,4 a US\$20,9 el $\mathrm{m}^{2}$ (J. Martínez, comunicación personal, 23 de abril de 2016).

La participación de la empresa en los problemas locales ha sido superficial. Esta fue la respuesta del alcalde:

Nos han apoyado pues digo muy poco [...] ellos han colaborado con nosotros, apenas hace tres meses o cuatro meses, no tengo exactamente la fecha, pero más o menos, se platicó con ellos y lograron ellos apoyarnos para la orquesta Esperanza Azteca San José Chiapa, junto con fundación Azteca, entonces hoy hay 200 niños de aquí de la cabecera municipal y de la región donde se están capacitando (...) Audi nos aportó los instrumentos, más o menos unos MXN\$3.000.000 invertidos en los instrumentos para los niños, fundación Azteca nos aporta los maestros y el municipio aportó las instalaciones y claro, los niños" (J. Martínez, comunicación personal, 23 de abril de 2016).

\section{Financiarización}

Según Soto (2013) el modelo neoliberal basado "en la inversión extranjera directa, bajo un esquema de estabilidad macroeconómica (inflación controlada, equilibrio o superávit fiscal y comercial) que permita alcanzar la modernización productiva" (p. 59), ha fallado. Daher (2013a) define la financiarización como "la construcción progresiva de movilidad/liquidez del capital de las firmas, sectores, regiones y naciones gracias a los 
mercados financieros" (p. 63). El mismo autor señala que "se trata de una amplia 'financiarización urbana' que incluye la vivienda social y que agudiza las disparidades e inequidades territoriales" (Daher, 2013b, p. 32).

Sus tres grandes repercusiones en el caso de San José Chiapa son el endeudamiento del Estado, las facilidades que se les proporcionan a las empresas extranjeras para que se instalen en su territorio, como es la exención de impuestos y la creación de nuevos impuestos para los pobladores.

Endeudamiento de $\$ \mathbf{1 4 . 9 7 7} \mathbf{~ m m d p}^{17}{ }^{18}$. Representa del orden de 520 veces el presupuesto de ingresos estimado del año 2017 del municipio de San José Chiapa, que es de $25 \mathrm{mdp}$. La plataforma para la armadora, se hizo a través del programa Proyectos de Prestación de Servicios (PPS), por lo que la entidad tendrá que pagar 5 mil 79 mdp, durante 11 años (Hernández, 2017, p. 2). Otros proyectos creados a partir de los PPS son el Centro de Convenciones, la estación de autobuses y el centro deportivo. Del endeudamiento global, del orden de 228.1 $\mathrm{mdp}^{19}, 1.5 \%$, representó la inversión en tierra (ver Tabla $1)$.

\footnotetext{
${ }^{17} \$ 784,136,125$ USD.

${ }^{18} \mathrm{Mmdp}=$ mil millones de pesos.

${ }^{19} \$ 11,937$ USD.
} 
Tabla 1

Inversiones estatales en tierra, infraestructura y obra pública para Audi y Ciudad Modelo

Tierra, infraestructura y obra pública

\section{Inversión (mdp)}

460 ha de tierra para la fábrica Audi (MXN\$85.000/ha)

39,1

929,04 ha de tierra para “Ciudad Modelo" o “Ciudad Audi" ( ${ }^{20}$ MXN\$170.0.000/ha)

157,94

60 ha de tierra para el Parque Finsa II (a MXN\$350.000/ha)

21

5 ha para relleno seco en Chiapa (MXN\$2.000.000/ha)

10

Construcción de Parque Finsa II

560

Construcción del relleno seco en Chiapa para "Ciudad Modelo"

Plataforma para la fábrica Audi (vía PPS)

5.790

9 ordenamientos que IDOM hizo para la "Ciudad Modelo" de Audi

Estación de bomberos

Hospital integral

49,6

Centro de Especialización para la industria automotriz

2.630

Centro Especializado para la Formación de Recursos Humanos

680

Caminos de acceso y perimetral a la planta

196,7

Ferrocarril (espuela)

861

Proyecto de infraestructura para el fomento industrial en la zona de San José Chiapa

Subestación eléctrica

164,8

Boulevard industrial automotriz

443,9

Tramo de la autopista Cuapiaxtla-Cuacnopalan

40,6

Centro de Convenciones, estación de autobuses y centro deportivo (vía PPS)

1.747

Líneas de agua potable, drenaje y alcantarillado

185,3

Parque lineal

71,7

Planta de tratamiento

38,2

Planta potabilizadora

57,9

Universidad Tecnológica Bilingüe Sustentable

80.8

Centro Escolar, CE (primaria, secundaria y bachillerato)

203

Vialidades urbanas

443,9

Centro Integral de Servicios (CIS)

Parque metropolitano central

77

Centro de salud

27

Zócalo, mercado y un monumento

20

\section{Total}

Fuentes de elaboración, propia con base en: Castillo (2016). Cuestiona José Juan Espinosa inversión morenovallista para Audi. [Nota periodística]. Intolerancia Diario; García, E. (2016a). Se han invertido más de $17 \mathrm{mmdp}$ en la planta Audi y Ciudad Modelo. [Nota periodística]. Milenio Puebla; García, E. (2016b). Concursan 3 obras más en Ciudad Modelo por 20 mdp. [Nota periodística]. Milenio Puebla; García, E. (2016c). Ejecutará estado 3 obras vía PPS por mil 747 mdp. [Nota periodística]. Milenio Puebla; García, E. (2016d). Gobierno estatal edificará relleno sanitario en Ciudad Modelo de Audi. [Nota periodística]. Milenio Puebla: García, F. (2016). Desaparecidos, los 9 ordenamientos que el IDOM hizo para "ciudad modelo" de Audi. [Nota periodística]. La Jornada de Oriente; Hernández, D. (2016). Compra estado terreno para el relleno seco en Chiapa. [Nota periodística]. Milenio Puebla; (s.a). (2016). Destinan casi 1,000 millones para pagar PPS en presupuesto 2017. [Nota periodística]. Diario Cambio.

\footnotetext{
${ }^{20}$ US\$0,89.
} 
La exención de impuestos para Audi. El 9 de diciembre de 2013 "el ejecutivo envió tres iniciativas para reformar las leyes de hacienda de San José Chiapa, Nopalucan y Mazapiltepec" (Pineda, 2013, p. 1), en las que exenta al $100 \%$ del pago a inversionistas en estos tres municipios relacionados con el impuesto predial, adquisición de bienes inmuebles y derechos de obras que no sea menor a un millón de pesos, durante los años 2014, 2015 y 2016 (Gobierno del Estado de Puebla (GEP), Secretaría General de Gobierno (SGG), Orden Jurídico Poblano (OJP), 2013). Uno de los acuerdos del convenio de Audi con el gobierno estatal es el de no aplicar en 30 años la contribución por mejoras.

El incremento de los impuestos para San José Chiapa. En el periódico El Sol de Puebla, del martes 3 de enero de 2017, se dio a conocer la siguiente noticia "Faculta Ley de Ingresos a Chiapa nuevos impuestos, justifica edil que es para mejorar servicios que ofrece el Ayuntamiento" (Miguel, 2017, p. 12a). En la nota se asienta que son entre 20 y 30 impuestos adicionales, resalta que se cobrarán "permisos de uso de suelo y autorizaciones por la colocación de anuncios espectaculares, lo cual no sucedía en el pasado" (Miguel, 2017, p. 12a). El alcalde no ofreció mayores detalles sobre los nuevos impuestos, sólo que éstos se aplicarán en la cabecera municipal y en los alrededores de Ciudad Modelo Audi, que se está edificando en dicho territorio. La Jornada de Oriente publicó que no son 20 ó 30 nuevos impuestos municipales sino diez, los que se cobrarán en el municipio (Rocha, 2017). De la comparación que se realizó de ambas leyes de ingresos 2016 y 2017 se constató que son 16 nuevos impuestos y derechos (ver Tabla 2).

Tabla 2

Diferencias entre la Ley de Ingresos del municipio de San José Chiapa para el ejercicio fiscal 2016 y 2017

\begin{tabular}{|c|c|c|}
\hline & $\begin{array}{l}\text { Ley de } \\
\text { Ingresos } 2016\end{array}$ & $\begin{array}{l}\text { Ley de } \\
\text { Ingresos } 2017\end{array}$ \\
\hline Primero, disposiciones generales, capítulo único & $\checkmark$ & $\checkmark$ \\
\hline Segundo, de los impuestos & $\checkmark$ & $\checkmark$ \\
\hline Del Impuesto Predial & $\checkmark$ & $\downarrow$ \\
\hline Del Impuesto sobre Adquisición de Bienes Inmuebles & $\checkmark$ & $\checkmark$ \\
\hline Del Impuesto sobre diversiones y espectáculos Públicos & $\checkmark$ & $\checkmark$ \\
\hline Del impuesto sobre Rifas, Loterías, Sorteos, Concursos y toda clase de juegos permitidos & $\checkmark$ & $\checkmark$ \\
\hline Tercero, de los Derechos & $\checkmark$ & $\checkmark$ \\
\hline De los derechos por obras materiales & $\checkmark$ & $\checkmark$ \\
\hline De los derechos por ejecución de obras públicas & 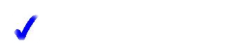 & $\checkmark$ \\
\hline De los derechos por los servicios de agua potable y drenaje. Para 2017, le quitaron la palabra potable. & $\checkmark$ & $\checkmark$ \\
\hline De los derechos por los servicios de agua potable, drenaje, alcantarillado, saneamiento de Ciudad Modelo & & + \\
\hline De la factibilidad para la prestación de los servicios públicos en materia hídrica & & + \\
\hline De la contratación de los servicios públicos & & + \\
\hline Del dispositivo de medición & & + \\
\hline Del pago por la prestación de los servicios públicos en tarifa & & + \\
\hline Suspensión de los servicios públicos & & + \\
\hline De las tarifas y cuotas especiales & & + \\
\hline De los depósitos, albercas y cisternas & & + \\
\hline $\begin{array}{l}\text { Autorización de proyectos, aprobación de planos, supervisión y revisión de obras hidráulicas, sanitarias y } \\
\text { pluviales }\end{array}$ & & + \\
\hline Permisos de descarga para usuarios no domésticos & & + \\
\hline
\end{tabular}


Otros servicios y documentos oficiales

Del servicio de agua de reúso

Infracciones y sanciones

De los derechos por el servicio del alumbrado público

De los derechos por expedición de certificaciones, constancias y otros servicios

De los derechos por los servicios de coordinación de actividades relacionadas con el sacrificio de animales

De los derechos por servicios de panteones

De los derechos por servicios especiales de recolección, transporte y disposición final de desechos sólidos

De los derechos por limpieza de predios no edificados

De los derechos por expedición de licencias, permisos o autorizaciones para establecimientos cuyos giros sean la enajenación de bebidas alcohólicas o la prestación de servicios

De los derechos por la expedición de licencias, permisos o autorizaciones para la colocación de anuncios y carteles o la realización de publicidad

De los derechos para expedición de licencias, permisos o autorización para negocios de bajo impacto e industria

De los derechos por ocupación de espacios del patrimonio público del municipio

De los derechos por los servicios prestados por el catastro municipal

De los derechos por servicios prestados por protección civil y por vialidad

\begin{tabular}{l}
\hline Cuarto, de los productos capítulo único \\
\hline Quinto, de los aprovechamientos \\
De los recargos \\
De las sanciones \\
De los gastos de ejecución \\
\hline Sexto, de las contribuciones de mejoras, capítulo único \\
\hline Séptimo, de las participaciones en ingresos federales y estatales, fondos y recursos participables, fondos de \\
aportaciones federales, incentivos económicos, reasignaciones y demás ingresos, capítulo único \\
\hline Octavo, de los ingresos extraordinarios, capítulo único \\
De los estímulos fiscales
\end{tabular}

Notas: $\sqrt{ }$ Está considerada en ambas leyes. \$ De nueva creación en 2017.

Fuentes: GEP, SGG, OJP. (2016). Ley de Ingresos del Municipio de San José Chiapa, Puebla, para el Ejercicio Fiscal 2016. Puebla: Autor; GEP, SGG, OJP. (2017). Ley de Ingresos del Municipio de San José Chiapa, Puebla, para el Ejercicio Fiscal 2017. Puebla: Autor.

La Ley de Ingresos del Municipio de San José Chiapa, Puebla, para el Ejercicio Fiscal 2016 fue de 42 páginas, con 51 artículos; la correspondiente a 2017 se incrementó a 83 páginas, con 120 artículos, precisamente el año cuando fue creado el Organismo Público Descentralizado Ciudad Modelo. Las diferencias encontradas son:

\section{La gestión y manipulación de la crisis}

Las crisis son procesos de selección social que, en la globalidad, se extiende a regiones y países desde donde se atrae personal calificado.

Discreta generación de empleos. El grupo automotriz invirtió 1.300 millones de dólares, en esta planta de San José Chiapa trabajan 3.800 empleados (Audi, México, 2014). En 2014, el Profesor Thomas Sigi, encargado del área de recursos humanos manifestó que: "Para nuestro trabajo en México tenemos hasta hoy cerca de $70 \mathrm{mil}$ solicitudes de empleo, un testimonio de la atracción de la 
marca Audi. En todos los continentes es un símbolo de calidad Premium".

El Gobernador del Estado, Rafael Moreno Valle (RMV), expresó que, con base en el convenio firmado con la armadora Audi, el mismo contempla penalizaciones. Si no cumple con la creación de 3.800 empleos, la armadora se haría acreedora a una sanción por \$55.000 USD por cada empleo que no se generará (Méndez, 2015).

El Sol de Puebla publicó una nota relacionada con la ocupación de estos empleos: “... personas provenientes de países como Alemania, Argentina y Brasil, quienes solicitaron vivir en Puebla a razón de la construcción de la planta de la empresa armadora Audi que tiene lugar en el municipio de San José Chiapa (Marcial, 2015, ver Imagen 4).

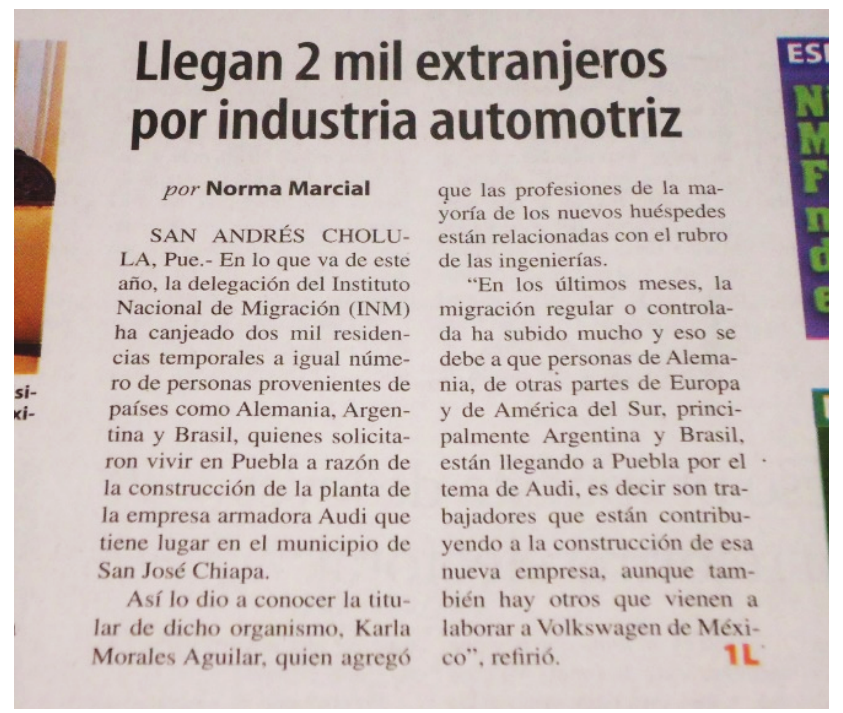

Imagen 4: Arribo de extranjeros por planta Audi.

Fuente de elaboración: Marcial, N. (2015). Llegan dos mil extranjeros por industria automotriz. [Nota periodística]. Recuperada de http://www.oem.com.mx/elsoldepuebla/notas/n3919465.htm

El 15 de agosto de 2016 (Anderson, 2016) informó que "es tal el imán en el que se ha convertido esta terminal que ya han recibido 230 mil solicitudes de empleo" (p. 2). "La generación de empleo para habitantes del municipio de San José Chiapa se esfumó. Audi sólo ha contratado a 10 trabajadores. Dos de planta y ocho son eventuales" (anónima, comunicación personal, 10 de noviembre de 2016). La empresa no tiene ningún interés en la vida de los habitantes del municipio y de la región porque su interés se concentró en los recursos naturales (tierra, agua, pastizales, montes) y en traer empleados de otros lugares y países, por eso los ejidatarios manifestaron su repudio a la nueva empresa, es el homo sacer como menciona Springer (2013), "vida que no cuenta para nada" (p. 608).

\section{Redistribuciones estatales}

El papel del Estado en el cambio de las leyes para adecuarlas a los requerimientos de las corporaciones. "Y por último, como uno de los roles más importantes que ha tenido el Estado facilitando la operatividad de las inversiones en tierras, está la autorización para desmontar campos, bosques y pastizales, perdiendo potestad sobre el patrimonio nacional" (Costantino, 2016, p. 144-145). Daher (2013c) señala "porque el recurso metropolitano, absorbiendo gran parte de la inversión pública y privada, hace crisis, sin embargo, en todos los frentes: crisis de crecimiento, crisis sociales y deterioro de la calidad de vida, depredación y contaminación del medio natural" (párrafo 8).

Se legitima legalmente la desposesión. El Gobierno estatal de Puebla y el Congreso del Estado sentaron las bases legales que eran necesarias para que la armadora AUDI se instalara sin problemas. Desde el Congreso del Estado se realizaron modificaciones a la Ley de Expropiación (2014), a la Ley General de Bienes del Estado (2012-2014), a la Ley de Organizaciones PúblicoPrivadas, se creó por Decreto el establecimiento de apoyos para el desarrollo, construcción, instalación y operación de empresas de manufactura y ensamblaje de automóviles (2012), se fundó el Fideicomiso Banco Estatal de Tierra (2011-2013), se decretó la Ley para la regularización de la propiedad inmobiliaria del Estado de Puebla (2015), de igual forma la importante Ley de Proyectos para Prestación de Servicios (2011, PPS), mediante la cual se construyeron las plataformas de Audi, entre otras. Con este propósito la Comisión de Hacienda y Patrimonio Municipal avaló cambios que resultaron en beneficio de la armadora.

La violencia y represión hacia los grupos marginados. En una entrevista con una ejidataria comentó: 
En San José Chiapa los campesinos y colonos nos manifestamos para exigir fuentes de empleo y que nos dejaran vender en tiendas de abarrotes $y$ comedores para los empleados de Audi, la empresa respondió con el cercamiento de la planta a través de una valla que puso justo enfrente en donde está la calle principal que llega a Audi desde San José Chiapa, fuimos reprimidos inmediatamente por la policía y el gobierno municipal impuso una multa de MXN\$100.000 a aquellos que intentaran manifestarse nuevamente" (anónima, comunicación personal, 10 de noviembre de 2016).

Otras expresiones de inconformidad son detenidas mediante la cooptación de los ejidatarios, por ejemplo:

Al momento de vender la tierra el propio gobernador hablo conmigo [Presidente del Comisariado Ejidal] para después marginarnos de todas las decisiones que hubo entre la empresa automotriz Audi y el

\section{Referencias}

Alanís, R. (2016). Va a juicio el ex secretario de Desarrollo Económico de NL. [Nota periodística]. Milenio Puebla.

Alfaro, R., Guízar, F., y Vizcarra I. (2011). El traslado fallido del aeropuerto internacional de la Ciudad de México a Texcoco. Argumentos, 24(65), 295-319. Recuperado de http://www.redalyc.org/articulo.oa?id=59519896011

Almeida Filho, N. \& Paulani, L. (2011). Regulação social e acumulação por espoliação: reflexão sobre a essencialidade das teses da financeirização e da natureza do estado na caracterização do capitalismo contemporâneo. Economia e Sociedade, 20(2), 243$272 . \quad$ https://dx.doi.org/10.1590/S010406182011000200002

Anderson, B. (2016). Esa Audi Q5 ... ni Obama la tiene (¿Y Moreno Valle?). [Nota periodística]. Milenio Puebla.

Audi México. (2014). ¿México estás preparado para lo que está por venir? Inauguración del Centro de Especialización. Puebla: Autor. gobierno del Estado de Puebla" (J. Gómez, comunicación personal, 18 de octubre de 2016).

\section{Discusión y conclusiones}

El gobierno participó en la compra de tierra que cedió a Audi. Ocultó a los campesinos para qué se utilizaría la tierra adquirida, para evitar que incrementaran el precio.

La diferencia entre el precio real y el precio de compra, fue a las finanzas de Audi. Audi no hizo gastos para la infraestructura. El gobierno pidió prestado y los habitantes de la región, vía impuestos, pagan esa deuda.

La crisis económica ha sido utilizada como pretexto para que la empresa se asiente porque traería empleos al lugar, situación que no se ha confirmado.

Los nuevos agentes han reordenado la relación de poder en la región. Los campesinos y sus organizaciones se han debilitado. Empresarios, agentes inmobiliarios, el comercio y los servicios, son los grupos hegemónicos.

Barrera, G. (2013). El paisaje de Real de Catorce: Un despojo histórico. Investigaciones Geográficas, 81, 110-125. https://dx.doi.org/10.14350/rig.32707

Bauman, Z. (2004). Modernidad líquida. Argentina: Fondo de Cultura Económica. (Trabajo original publicado en 2002).

Bojórquez, J. y Ángeles, M. (2014). Expansión turística y acumulación por desposesión: El caso de Cabo San Lucas, Baja California Sur (México). Revista Colombiana de Geografía, 23(2), 179-202. Recuperado de http://www.redalyc.org/articulo.oa?id=28183070401 2

Borras Jr., S. y Franco, J. (2010). La política del acaparamiento mundial de tierras: replanteando las cuestiones de tierras, redefiniendo la resistencia. Transnational Institute, 1. Recuperado de: http://www.tni.org/sites/www.tni.org/files/La\%20pol \%C3\%ADtica\%20del\%20acaparamiento\%20mundial\% 20de\%20tierras.pdf

Cáceres, D. (2015). Accumulation by Dispossession and Socio-Environmental Conflicts Caused by the Expansion of Agribusiness in Argentina. Journal of 
Agrarian Change, 15(1), 116-147. https://dx.doi.org/10.1111/joac.12057

Casgrain, A., y Janoschka, M. (2013). Gentrificación y resistencia en las ciudades latinoamericanas: EI ejemplo de Santiago de Chile. Andamios, 10(22), 19$44 . \quad$ Recuperado de http://www.scielo.org.mx/scielo.php?script=sci_artte xt\&pid=S1870-00632013000200003\&lng=es\&tlng=es

Castillo, J. (2016). Cuestiona José Juan Espinosa inversión morenovallista para Audi. [Nota periodística]. Intolerancia Diario.

Composto, C. y Rabasa, M. (2011). Entrevista con David Harvey. Nuevo imperialismo y cambio social: entre el despojo y la recuperación de los bienes comunes. Revista Herramienta Debate y Crítica Marxista. Recuperado de http://www.herramienta.com.ar/entrevistas/entrevis ta-con-david-harvey-nuevo-imperialismo-y-cambiosocial-entre-el-despojo-y-la-rec

Contreras, Y. (2011). La recuperación urbana y residencial del centro de Santiago: nuevos habitantes, cambios socioespaciales significativos. EURE, 37(112), 89-113. https://dx.doi.org/10.4067/S025071612011000300005

Costantino, A. (2016). El capital extranjero y el acaparamiento de tierras: conflictos sociales y acumulación por desposesión en Argentina. Revista de Estudios Sociales, 55(35), 137-149. https://dx.doi.org/10.7440/res55.2016.09

Daher, A. (2013a). El sector inmobiliario y las crisis económicas. $\quad$ EURE, 39(118), 47-76. https://dx.doi.org/10.4067/S025071612013000300003

Daher, A. (2013b). Fondos inmobiliarios y riesgo urbano. Revista de Urbanismo, 29, 32-45. https://dx.doi.org/10.5354/0717-5051.2013.30303

Daher, A. (2013c). Territorios de la financiarización urbana y de las crisis inmobiliarias. Revista de Geografía Norte Grande, 56, 7-30. https://dx.doi.org/10.4067/S071834022013000300002
Davidson, M. \& Lees, L. (2010). New-build gentrification: Its histories, trajectories, and critical geographies. Population. Space Place, 16, 395-411. https://dx.doi:10.1002/psp.584

De Mattos, C. (2016). Financiarización, valorización inmobiliaria del capital y mercantilización de la metamorfosis urbana. Sociologías, 18(42), 24-52. https://dx.doi.org/10.1590/15174522-018004202

Diego, R. (2014). Actores sociales rurales y la nación mexicana frente a los megaproyectos mineros. Problemas del Desarrollo. Revista Latinoamericana de Economía, 45, 159-180. Recuperado de http://www.redalyc.org/articulo.oa?id=11832064008

e-consulta. (2014). Española IDOM entrega avance de la Ciudad Audi. [Nota periodística]. Puebla: Autor.

Enciclopedia de los Municipios y Delegaciones de México. (s.f). La región III y IV de Puebla en: http://www.inafed.gob.mx/work/enciclopedia/EMM2 1puebla/regionalizacion.html

Fair, H. (2010). El debate político entre los enfoques marxista, posmarxistas y posmodernos. La lámpara de Diógenes, Revista de Filosofía, 11(20-21), 237-260. http://www.redalyc.org/pdf/844/8L41840006.pdf

García, E. (2016a). Se han invertido más de 17 mmdp en la planta Audi y Ciudad Modelo. [Nota periodística]. Milenio Puebla.

García, E. (2016b). Concursan 3 obras más en Ciudad Modelo por $20 \mathrm{mdp}$. [Nota periodística]. Milenio Puebla.

García, E. (2016c). Ejecutará estado 3 obras vía PPS por mil 747 mdp. [Nota periodística]. Milenio Puebla.

García, E. (2016d). Gobierno estatal edificará relleno sanitario en Ciudad Modelo de Audi. [Nota periodística]. Milenio Puebla.

García, F. (2016). Desaparecidos, los nueve ordenamientos que el IDOM hizo para "ciudad modelo" de Audi. [Nota periodística]. La Jornada de Oriente.

Garibay, C. y Balzaretti, A. (2009). Goldcorp y la reciprocidad negativa en el paisaje minero de Mezcala, Guerrero. Desacatos, 30, 91-110. Recuperado 
http://www.scielo.org.mx/scielo.php?script=sci_artte xt\&pid=S1405-92742009000200007\&lng=es\&tIng=es

Garibay, C., Boni, A., Panico, F., y Urquijo, P. (2014). Corporación minera, colusión gubernamental y desposesión campesina. El caso de Goldcorp Inc. en Mazapil, Zacatecas. Desacatos, 44, 113-142. Recuperado de http://www.scielo.org.mx/scielo.php?script=sci_artte xt\&pid=S1405-92742014000100009\&lng=en\&tIng=en

Gobierno del Estado de Puebla (GEP), Secretaría General de Gobierno (SGG), Orden Jurídico Poblano (OJP) (2013). Ley de Hacienda para el municipio de San José Chiapa, Reforma a los artículos 130, 131 y 132.

Puebla: Autor.

GEP, SGG, OJP (2015a). Decreto del Honorable Congreso del Estado por virtud del cual se autoriza al titular del Poder Ejecutivo del Estado, a realizar los trámites necesarios para llevar a cabo la transmisión de la propiedad de los bienes inmuebles correspondientes al Sitio del Proyecto, en términos del contrato del desarrollo suscrito por el Gobierno del Estado de Puebla con AUDI automotive, S.A. de C.V. y Volkswagen de México, S.A. de C.V. 19 de septiembre de 2012.

GEP, SGG, OJP (2015b). Decreto: Se autoriza la adhesión del Honorable Ayuntamiento del Municipio de San José Chiapa, Puebla al Convenio de Desarrollo celebrado entre el Estado de Puebla con AUDI automotive, S.A. de C.V. y Volkswagen de México, S.A. de C.V, 19 de septiembre de 2012.

GEP, SGG, OJP. (2016). Ley de Ingresos del Municipio de San José Chiapa, Puebla, para el Ejercicio Fiscal 2016. Puebla: Autor.

GEP, SGG, OJP. (2017). Ley de Ingresos del Municipio de San José Chiapa, Puebla, para el Ejercicio Fiscal 2017. Puebla: Autor.

Gómez, S. (2015). Orden global y acumulación por desposesión en Argentina (1990-2012). Finisterra, 99, 119-141. https://dx.doi.org/10.18055/Finis3144

González, L. (2012). Puebla se queda con la planta Audi [Nota periodística]. Recuperada de: http://www.eleconomista.com.mx/industrias/2012/0 9/04/puebla-se-queda-planta-audi
Guerra, D. y Skewes, J. (2010). Acumulación por desposesión y respuestas locales en el remodelaje de los paisajes estuariales del sur de Chile. Chungará (Arica), 42(2), 451-463. https://dx.doi.org/10.4067/s071773562010000200008

Hall, D. (2013). Primitive accumulation, accumulation by dispossession and the Global Land Grab. Third World Quarterly, 34(9), 1582-1604. https://dx.doi.org/10.1080/01436597.2013.843854

Harvey, D. (2005). El "nuevo" imperialismo: acumulación por desposesión. Buenos Aires: Clacso. Recuperado de http://biblioteca.clacso.org.ar/clacso/se/2013070212 0830/harvey.pdf

Harvey, D. (2007). Breve historia del neoliberalismo. Madrid: Akal. Recuperado de https://teoriaeconomicatercersemestreri.files.wordpr ess.com/2012/09/breve-historia-del-neolibera

Harvey, D. (2010). Organización para la transición anticapitalista. Argumentos, 23(63), 35-58. Recuperado de

http://www.scielo.org.mx/scielo.php?script=sci_artte $\underline{x t \& p i d=S 0187-57952010000200003 \& \operatorname{lng}=e s \& t \operatorname{lng}=e s}$

Hernández, D. (2016). Compra estado terreno para el relleno seco en Chiapa. [Nota periodística]. Milenio Puebla.

Hernández, M. (2015). Anuncia Moreno Valle "regularización del uso de la tierra" para ciudad Audi en Chiapa. [Nota periodística]. La Jornada de Oriente. Recuperado de http://www.lajornadadeoriente.com.mx

Hidalgo, R. (2004). De los pequeños condominios a la ciudad vallada: las urbanizaciones cerradas y la nueva geografía social en Santiago de Chile (1990-2000). EURE, 30(91), 29-52. https://dx.doi.org/10.4067/S025071612004009100003

Hogan, T., Bunnell, T., Pow, C-P., Permanasari, E., \& Morshidi, S. (2012). Asian urbanisms and the privatization of cities. Cities, 29, 59-63. https://dx.doi:10.1016/j.cities.2011.01.001

H. Congreso del Estado de Puebla (HCEP), Comisión de Hacienda y Patrimonio Municipal (CHPM) (2012a). 
"Acta de la reunión de la Comisión de Hacienda y Patrimonio Municipal" celebrada el lunes veintitrés de julio de dos mil doce, Puebla, Puebla.

H.CEP, CHPM (2012b). "Acta de la reunión de la Comisión de Hacienda y Patrimonio Municipal" celebrada el veinticinco de julio de dos mil doce, Puebla, Puebla.

H.CEP, (2012c). "Acta de la Reunión de la Comisión de Hacienda y Patrimonio Municipal", celebrada el viernes 14 de septiembre de 2012, Puebla, Puebla, Recuperado de http://congresopuebla.gob.mx/index.php?option=co $\underline{\text { m_docman\&task=cat_view } \& \text { gid }=145 \& \text { Itemid }=128 \& l i}$ mitstart $=20$

Instituto Nacional de Estadística y Geografía (INEGI). (2010a). México en cifras. Información nacional, por entidad federativa y municipios. Recuperado de http://www.inegi.org.mx/

INEGI. (2010b). Marco Geoestadístico Nacional.

Instituto Nacional para el Federalismo y el Desarrollo Municipal (INAFED). (2015). Recuperado de: http://www.snim.rami.gob.mx/

Inzulza-Contardo, J. (2016). Contemporary Latin American gentrification? Young urban professionals (YUPs) discovering historic neighbourhoods, Urban Geography, $37(8)$, 1195-1214. https://doi.org/10.1080/02723638.2016.1147754

Janoschka, M. (2016). Gentrificación, desplazamiento, desposesión: procesos urbanos claves en América Latina. Revista INVI, 31(88), 27-71. https://dx.doi.org/10.4067/s071883582016000300002

López-Morales, E. (2013). Gentrificación en Chile: aportes conceptuales y evidencias para una discusión necesaria. Revista de Geografía Norte Grande, 56, 31$52 . \quad$ https://dx.doi.org/10.4067/S0718$\underline{34022013000300003}$

Marcial, N. (2015). Arriban dos mil extranjeros a la armadora Audi. [Nota periodística]. Recuperada de http://www.oem.com.mx/elsoldepuebla/notas/n391 9465.htm

Martínez, J. (2012). Audi es para Puebla. [Nota periodística]. El Sol de Puebla.
Méndez, P. (2015). Multa de 55 mil dólares a Audi por cada empleo que no genere. [Nota periodística]. econsulta.com. Recuperada de http://www.econsulta.com/nota/2015-10-05/gobierno/gobiernomultaria-audi-si-no-cumple-con-empleos-prometidos

Merchand, M. (2012). Estado neoliberal y acumulación por desposesión a favor del capital global financiero. Apuntes del Cenes, 31(54), 73-100. https://dx.doi.org/10.19053/22565779.15

Merchand, M. (2013). El Estado en el proceso de acumulación por desposesión favorece la transnacionalización de la minería de oro y plata en México. Paradigma Económico, 5(1), 107-141.

Merchand, M. (2015). Estado y acumulación por despojo en el sector energético en México. Ágora, 17(1), 75 86. https://dx.doi.org/10.17058/agora.v17i1.5719

Miguel, A. (2017). Faculta Ley de Ingresos a Chiapa nuevos impuestos. [Nota periodística]. El Sol de Puebla.

Nateras, M. (2005). La importancia del método en la investigación. Espacios públicos, 8(15), 277-285. http://www.redalyc.org/articulo.da?id-67681519

Perreault, T. (2013). Dispossession by accumulation? Mining, water and the nature of enclosure on the Bolivian Altiplano. Antipode, 45(5), 1050-1069. https://dx.doi.org/10.1111/anti.12005

Pineda, M. (2013). Plantea RMV exentar impuestos por 3 años a empresas como Audi [Nota periodística]. Recuperada de e-consulta.com.

Presidencia de la República. (2015). Inauguración camino acceso a la zona industrial San José Chiapa. Recuperado de http://www.gob.mx/presidencia/prensa/diversasintervenciones-inauguracion-camino-acceso-a-lazona-industrial-san-jose-chiapa-y-distribuidor-vialnumero-9-periferico-ecologico

Roberts, A. (2008). Privatizing social reproduction: The primitive accumulation of water in an Era of Neoliberalism. Antipode, 40(4), 535-560. https://dx.doi.org/10.1111/j.1467-8330.2008.00623.x

Rocha, C. (2017). En San José Chiapa se cobrarán 10 nuevos impuestos que ni el Secretario General conoce. [Nota Periodística]. La Jornada de Oriente. 
Rojas, I. (2011). Elementos para el diseño de técnicas de investigación: una propuesta de definiciones y procedimientos en la investigación científica. Tiempo de Educar, 12(24), 277-297. http://www.redalyc.org/articulo.oa?id=31121089006

Rueda, A. (2012). Con Audi, una nueva era de desarrollo industrial: Rafael Moreno Valle (RMV). [Nota periodística]. Recuperada de: http://www.diariocambio.com.mx

Sánchez, A. y Hurtado, M. (Coords). (2016). San José Chiapa, Puebla, México ante la llegada de Audi, Tomo I. Puebla: BUAP, Facultad de Arquitectura.

Sánchez, A., Teutli, M., Hurtado, M., Saloma M. y Mendoza, P. (2016). Status of the Issue of the Region of San José Chiapa, Puebla, Mexico, before the Arrival of AUDI. Procedia Environmental Sciences, 34, 641650. https://doi.org/10.1016/j.proenv.2016.04.056

Santos, C. (2014). Naturalismos y acumulación por desposesión: Paradojas del desarrollo sustentable. Horizontes Antropológicos, 20(41), 331-350. Recuperado de https://dx.doi.org/10.1590/S010471832014000100012

Secretaría de Gobernación, SEGOB, Instituto Nacional para el Federalismo y el Desarrollo Municipal, INAFED y Gobierno del Estado de Puebla (GEP). (2010). Enciclopedia de los Municipios y Delegaciones de México, Estado de Puebla. Ciudad de México: Autor.

Soto, R. (2013). América Latina. Entre la financiarización y el financiamiento productivo. Problemas del
Desarrollo. Revista Latinoamericana de Economía, 44(173), 57-78. https://dx.doi.org/10.1016/S03017036(13)71875-3

Springer, S. (2013). Violent Accumulation: A postanarchist critique of property, dispossession, and the state of exception in neoliberalizing Cambodia. Annals of the Association of American Geographers, 103(3), 608 626. https://dx.doi.org/10.1080/00045608.2011.628259

Theodore, N., Peck, J., y Brenner, N. (2009). Urbanismo neoliberal: la ciudad y el imperio de los mercados. Temas Sociales, 66, 1-12. Recuperado de http://www.sitiosur.cl/r.php?id=898

Torres, C. (2015). Entrevista a David Harvey en la Universidad Nacional de Colombia. Bitácora, 1(25), 165-167. https://doi.org/10.15446/bitacora.v1n25.53217

Vite, M. (2012). Una interpretación heterodoxa de la crisis financiera global. Espiral, 19(55), 09-37. Recuperado de http://www.scielo.org.mx/scielo.php?script=sci_artte xt\&pid=S1665-05652012000300001\&lng=es\&tlng=es 